\section{B493 and B9304, Carrot Inbreds for Use in Breeding, Genetics, and Tissue Culture}

\author{
P.W. Simon ${ }^{1}$ and C.E. Peterson ${ }^{2}$ \\ U.S. Department of Agriculture, Agricultural Research Service, \\ Department of Horticulture, University of Wisconsin, Madison, WI 53706
}

\author{
W.H. Gabelman ${ }^{3}$ \\ Department of Horticulture, University of Wisconsin; Madison, WI 53706
}

Additional index words. Daucus carota, vegetable breeding, hybrid tester, flavor, terpenoids

Progress in carrot genetical analysis and breeding depends upon the availability of uniform, inbred testers of diverse genetic background. Homozygous carrot inbreds of known genetic origin can also be useful starting material for tissue culture research (Simon, 1984, 1985). Carrot inbreds B493 and B9304 have been selected for use in breeding, genetic, and tissue culture studies.

\section{Origin}

B493 was derived from a cross made in 1968 at the Univ. of Wisconsin between B8549 (a high-solids, Imperator-shaped inbred from 'Long Chantenay') and B5931 (a dark orange inbred from 'Imperator 58' used as a parent in the hybrids 'Spartan Sweet' and 'Spartan Bonus'). Selection was based on improving color and 'Imperator' shape for eight generations beyond the $\mathrm{F}_{2}$. Beginning in the $\mathrm{F}_{2} \mathrm{M}_{3} \mathrm{~S}_{5}$ generation, selection was made among 14 sibling populations for high volatile terpenoid content, low bisabolene content (in contrast to typically high levels of this terpenoid found in carrots), and sustained vigor with inbreeding. Self-pollination was continued for six more generations in one population and followed by two generations of mass pollination to increase seed

\footnotetext{
Received for publication 3 Aug. 1989. Research supported by USDA, ARS, and College of Agriculture and Life Sciences, Univ. of WisconsinMadison. The cost of publishing this paper was defrayed in part by the payment of page charges. Under postal regulations, this paper therefore must be hereby marked advertisement solely to indicate this fact.

'Research Geneticist and Associate Professor.

${ }^{2}$ Research Horticulturist and Professor (deceased). ${ }^{3}$ Professor.
}

supplies. B493 is in the $\mathrm{F}_{2} \mathrm{M}_{3} \mathrm{~S}_{11} \mathrm{M}_{2}$ generation and no longer segregates for shape, color, volatile terpenoids, or sugar type. Since B493 is so highly inbred, it is suitable as a homozygous parent in carrot genetic, biochemistry, and physiology research. B9304 was derived from a cross made in 1972 at the Univ. of Wisconsin between W33 (a uniformly dark orange tapered inbred from a cross between 'Hutchinson' and 'Tendersweet') and B10138 (a dark orange Danversshaped inbred from 'Danvers 126'). For three generations of self-pollination beyond the $\mathrm{F}_{2}$, selection was exercised for dark orange color" and 'Danvers' shape.

In the $\mathrm{F}_{3}$ generation, selection was initiated for mild flavor, low volatile terpenoid content, succulent texture, and high reducing sugar content among seven sibling populations of W33 $\times$ B10138. Selection for desirable eating quality was continued for each of these populations over four generations of mass pollination. B9304 was derived from one of these populations in the $\mathrm{F}_{5} \mathrm{M}_{5}$ generation. B9304 no longer segregates for shape, color, volatile terpenoids, flavor, or sugar type.

\section{Description}

Mature roots of B493 are $2 \mathrm{~cm}$ in diameter at the crown and 15 to $20 \mathrm{~cm}$ long, tapered, and deep orange. B493 has been tested for use in tissue culture, where it readily produces callus and suspension cultures and easily regenerates on solid medium or in liquid culture. Sucrose predominates in the free sugars stored in B493 roots. Therefore, B493 is rs/ $r s$ (Freeman and Simon, 1983). Volatile terpenoid content surpasses $110 \mathrm{ppm}(<1 \%$ of this is bisabolene), whereas the carotene content of B493 ranges from 180 to 210 ppm, depending on growing conditions. Its dark orange color and 'Imperator' shape make it suitable as a fresh-market carrot inbred tester and for developing and testing fresh-market germplasm. A petaloid cytosterile counterpart of B493 is now at $\mathrm{BC}_{12}$.

Mature roots of B9304 are 4 to $5 \mathrm{~cm}$ in diameter at the crown, cylindrical, blunt, and 12 to $15 \mathrm{~cm}$ long. Sensory evaluation panels have consistently rated B9304 as mildest in flavor and very crisp or succulent in comparison with a wide range of U.S. inbreds. B9304 roots have uniformly high reducing sugar $(R s / R s)$ (Freeman and Simon, 1983), very low volatile terpenoids (10 to $15 \mathrm{ppm}$ ), crisp succulent texture, 'Danvers' shape, and carotene content of 90 to $125 \mathrm{ppm}$, depending upon growing conditions. B9304 has been tested for use in tissue culture; where it proves to be a slow producer of callus and suspension cultures and difficult to regenerate. It is suitable as a processing carrot inbred tester and its excellent culinary quality makes it useful for developing high quality germplasm. B9304 is one parent of carrot inbred B2566 (Simon et al., 1987). B9304 is a partially sterile male parent (Hansche and Gabelman, 1963; Struckmeyer and Simon, 1986). A petaloid cytosterile counterpart of B9304 is now at $\mathrm{BC}_{7}$.

\section{Availability}

Inquiry regarding seed availability for carrot inbreds B493 and B9304 should be directed to P.W.S.

\section{Literature Cited}

Freeman, R.E. and P.W. Simon. 1983. Evidence for simple genetic control of sugar type in carrot (Daucus carota L.). J. Amer. Soc. Hort. Sci. 108:50-54

Hansche, P.E. and W.H. Gabelman. 1963. Phenotypic stability of pollen sterile carrots, Daucus carota L. Proc. Amer. Soc. Hort. Sci. 82:341-350.

Simon, P.W. 1984. Carrot genetics. Plant Molecular Biol. Rptr. 2:54-63.

Simon, P.W. 1985. Use and improvement of carrot for genetic studies, p. 194-198. In: M. Terzi, L. Pitto, and R. Sung (eds.). Somatic embryogenesis of carrots. Consiglio Nazionale delle Richerche, Increment Produttivita Risorse Agricole, Rome.

Simon, P. W., C.E. Peterson, M. Bassett, J.V. Strandberg, J.M. White, and V.E. Rubatzky. 1987. B2566 carrot inbred. HortScience 22:327.

Struckmeyer. B.E. and P.W. Simon. 1986. Anatomy of fertile and male-sterile carrot flowers from different genetic sources. J. Amer. Sot. Hort. Sci. 11(6):965-968. 